\title{
Physical Properties and Biological Activity of Some Novel HCV NS3 Protease Inhibitors
}

\author{
Noha A. Saleh \\ Biophysics Department, Faculty of Science, Cairo University, Giza 12613, Egypt
}

\begin{abstract}
$\mathbf{T}$ HEORETICAL molecular modelling mimics the physical, chemical and biological properties and the behavior of molecules using classical and quantum theoretical methods. Egypt is considered the most infected region in the world with hepatitis $\mathrm{C}$ virus (HCV) especially genotype 4a. The most important target enzyme for HCV inhibition is nonstructural 3 protease (NS3). Based on recent theoretical study, a possible potent inhibitor is a dimer cellulose with hexapeptide at position 6 . In the present study, the physical properties and biological activity of suggested novel NS3 protease inhibitors for Egyptian genotype 4 are calculated using Parametrization method 3(PM3). These inhibitors are divided into two series. The first series is the dimer cellulose with hexapeptide modifications using $\beta$-amino acids, mix of $\alpha$ - and $\beta$-amino acids, $\alpha$-ketoacids or phenyl acyl sulfonamide. The second series consists of a monomer cellulose instead of dimer cellulose with the same modifications in the hexapeptide sequences. Results show that, the two compounds with $\alpha$-ketoacids in the first and second series have better physical properties as well as nearly similar biological activity compared to the recently studied inhibitor without any modifications.
\end{abstract}

Keywords: Biological activity, Docking, HCV, Molecular modelling, NS3 protease, Physical properties, PM3.

\section{Introduction}

The physical, chemical and biological properties of any compound, molecule or molecular system can be simulated using the theoretical methods of molecular modelling. Molecular modelling is associated withcomputer modelling and computer-based methods that depend on experimental data and basic laws of physics (classical or quantum laws) for understandingand predicting the behavior of molecularsystems. This technique enables calculation or predictionof the geometry optimization, molecular energies and structures, energies and structures of transition states, bond energies, molecular orbitals, thermodynamic properties, atomic charges and electrostatic potential, vibrational frequencies, UV, IR, Raman \& NMR spectra, polarizabilities and hyperpolarizabilities, magnetic properties, ionization potential, electron affinity, proton affinity, surface properties, reaction pathway, chemical reactivity andmultipole moments.In addition to the prediction of biological properties to understand the structure-activity relationships and rational drug design [1-6].Therefore, theoretical molecular modeling helps in selecting the possibly best molecule to synthesize, thus, saving efforts, time and money.

Drug design is the most important part of the development of drugs including protein-based drugs. Drug design process is finding or creating a molecule to give a specific activity on a biological organism. Rational drug design is based on the biological properties of molecules that are related to their actual structural features. The discovery and development of drug is a time - consuming, expensive, and interdisciplinary process. Molecular modeling facilitates the way to the discovery of lead structures by a rational approach $[2,7,8]$. Computational molecular modelling technology is becoming indispensable approach to accelerate and decrease the costs of the drug development. This helps in the design, selection, and lead identification of novel inhibitors and compounds. Computational approaches in medicinal chemistry techniques used to study the structure and predict the biological activity of drug is called Computer-Aided Drug Design (CADD) [9-11]. 
Side by side, the CADD technologies and drug discovery approaches in researches could lead to a reduction of the drug design cost up to $50 \%$. The applications of CADD cover two major areas; structure-based drug design and ligandbased drug design. The most essential process in structure-based drug design is docking simulation. Molecular docking involves a protein-ligand or protein-protein complex simulation that is used to predict the ligand's orientation and conformations inside a protein receptor or enzyme [8-15]. On the other hand, essential field in ligandbased drug design is Quantitative StructureActivity Relationship (QSAR). The classical QSARdescriptors are calculated by statistics and by mathematical equationsthat give relationships betweenthe biological property and structure within a family of compounds $[10,11,16,17]$.

One of the essential applications of CADD is the development of inhibitorssuch as anti-hepatitis $\mathrm{C}$ virus [18-27]. Hepatitis $\mathrm{C}$ virus (HCV) is a third type of hepatitis virus discovered after hepatitis A and B in 1970. Its genome was identified in 1989 [28]. Hepatitis $\mathrm{C}$ virus is responsible for liver disease reported worldwide ( $\sim 3 \%$ of the world's population, 150-200 million people) especially the high prevalence in Asia and North of Africa $[29,30]$. Over $85 \%$ of $\mathrm{HCV}$ infected people will develop chronic hepatitis which may progress to liver cirrhosis and Hepatocellular Carcinoma (HCC) $[31,32] . \mathrm{HCV}$ is a single positive-strand RNA and one member of the Flaviviridae family. $\mathrm{HCV}$ genome encodes to 10 polypeptides, each with a distinct function. These functional proteins are four structural proteins (C, E1, E2 and p7) and sixnon-structural proteins (NS2, NS3, NS4A, NS4B, NS5A, and NS5B)[33-39].

The highest HCV infection percentage worldwide is in Egypt (with almost $20 \%$ of the population being infected). The most common sub-genotype in Egypt is 4a [40-42].Up till now, there is no vaccine for the prevention of HCV infection. The current therapy is a combination of Interferon alpha (IFN) with the antiviral ribavirin which is effective in $50-80 \%$ of patients, expensive and associated with many side effects [43-46]. However, recently some inhibitors targeting HCV NS3 protease, NS5B or NS5A,have been approved as HCV inhibitors [46-48]. Still there is a need to investigate more effective anti-HCV compounds.

Recently, structure-based drug design is performed to study the inhibition activity of novel compounds such as HCV NS3 protease inhibitors [24]. These inhibitors consist of dimmer cellulose and hexa-peptide sequences at different positions on cellulose. The hexa-peptide sequences is the NS5A/NS5B junction for the Egyptian genotype 4 (Glu-Asp-Val-Val-Cys-Cys) consequently, it represents a natural substrate [41,42]. According to this study, the compound with hexa-peptide sequences attached to dimmer cellulose at position 6 has good inhibition activity against HCV NS3 protease [24].

Based on some previous experimental and theoretical studies, the modification of peptide chain of HCV NS3 protease with $\beta$-amino acid [49] or mix of $\alpha$ - and $\beta$-amino acids [49] or $\alpha$-ketoacids [50-52] orphenyl acyl sulfonamide [53,54] provides an impressive increase in the potencyof $\mathrm{HCV}$ inhibition activity. Therefore, this work introduces a redesigningof such compoundsby performing two main modifications. The first modification is in the hexapeptide sequences by replacing the $\alpha$ aminoacids sequences with $\beta$-amino acids, mix of $\alpha$ - and $\beta$-amino acids, $\alpha$-ketoacids instead of the thiol group (SH) of cysteine residues or phenyl acyl sulfonamide instead of the C-terminal carboxylic acid. The second modification is replacing dimmer cellulose with monomer cellulose (Table 1).In this study combined methods of docking and QSAR are used to evaluate the physical properties and biological activity of suggested compounds, in addition to improve the analysis andselection of good compoundsworking as HCV NS3 protease inhibitors.

\section{Computational details:}

SCIGRESS 3.0 software [55] is used to build the suggested compounds as well as to calculate the physical properties(QSAR descriptors) and biological activity (molecular docking simulation).

\section{The physical properties:}

The geometry of studied compounds are optimized at lowest total energy by calculation using PM3 method [56]. Then geometries having the lowest energies are confirmed by calculating the vibrational modes of compounds at the same level of the calculation method (PM3). After confirming that the optimized geometries of the suggested compounds are located inthe global minimum, not in transition state, the physical properties are calculated at PM3 level. Thephysical properties of introduced compounds are represented by QSAR descriptors. The included physical descriptors (or 
properties) in this study are:total energy, electron affinity, ionization potential, frontier molecular orbital energy gap $(\Delta \mathrm{E})$, heat of formation, dipole moment, $\log \mathrm{P}$, solvent accessible surface area, surface area and volume.

\section{The biological activity}

The biological activity of proposed compounds arepredicted by docking simulation between the compounds or ligands and the HCV $\mathrm{NS} 3$ protease. The HCV NS3 protease used in docking calculation is PDB code:3LOX from the Protein Data Bank [57]. The optimized geometry of protease is calculated at MM3 level of calculation after adding hydrogen atoms [58]. The His57, Asp81 and Ser139 (conserved catalytic triad residues of HCV NS3 protease active site) and Gly137 are selected as an active site group. FASTDOCK and PMF04 [59] scoring functions utilizing a genetic algorithm are used in order tofind the best score for inhibition activity among the studied compounds.Both, ligands and selected HCV NS3 protease active site residues are flexible during the molecular docking calculations. The best scores docking systems are re-optimized via MM3 method to calculate the binding free energy. The binding energy is calculated according to the following equation[24]:

\section{Results and Discussion}

The previous study in 2017 had suggested dimer cellulose attached to natural substrate (Glu-Asp-Val-Val-Cys-Cys) at position 6 as a promising $\mathrm{HCV}$ NS3 protease inhibitor (Fig.1) [24]. In this study, some potent modifications are introduced to this promising inhibitors (parent compound). These modifications target to improve the inhibition activity against $\mathrm{HCV}$ NS3 protease activity.This is elucidated by calculating the physical properties and biological activity of suggested compounds. The suggested modifications are divided into two series. The first series is the modification in sequence of the natural substrate to form compounds 1, 2, 3 and 4 (Fig.2). Compound 1 has $\beta$-amino acids, compound 2 hasmix of $\alpha$ - and $\beta$-amino acids, while compound 3 has $\alpha$-ketoacids instead of the thiol group ( $\mathrm{SH}$ ) of cysteine residues and compound 4 has phenyl acyl sulfonamide instead of the C-terminal carboxylic acid (Table 1). The second series represents a decrease inthe dimension of suggested compounds by introducing only monomer cellulose instead of dimer cellulose with the same modification in natural substrate sequences (Fig.2).These form compounds 5, 6, 7, 8 and 9 as shown in table 1 . The second modification is a trial to decrease the area of compounds since the HCV NS3 protease is shallow, so small molecules may produce good inhibition activity. Figure 3 represents the geometrical structure of optimized parent and suggested compounds at PM3 method.

\section{The physical properties}

Some physical properties of the parent compound at position 6 and its modified compoundsare listed in Table 2 and calculated at semi-empirical theoretical level; PM3 method. These physical descriptors aretotal energy, electron affinity,ionizationpotential, frontier molecular orbital energy $\operatorname{gap}(\Delta \mathrm{E})$, heat of formation, dipole moment, $\log \mathrm{P}$, solvent accessible surface area, surface area and volume. The stability of the compounds are determined by the value of total energy. As the total energy decreases, the compound stability increases. Total energy values vary from the lowest value; $-411014.94 \mathrm{kcal} / \mathrm{mol}$ for compound 3 with $\alpha$-ketoacids; to the highest value; $-299082.55 \mathrm{kcal} /$ mol for compound 5 with $\alpha$-amino acids. The compound 3 with $\alpha$-ketoacids and compound 4 with phenyl acyl sulfonamide are the most stable based on their total energies of $-411014.94 \mathrm{kcal} /$

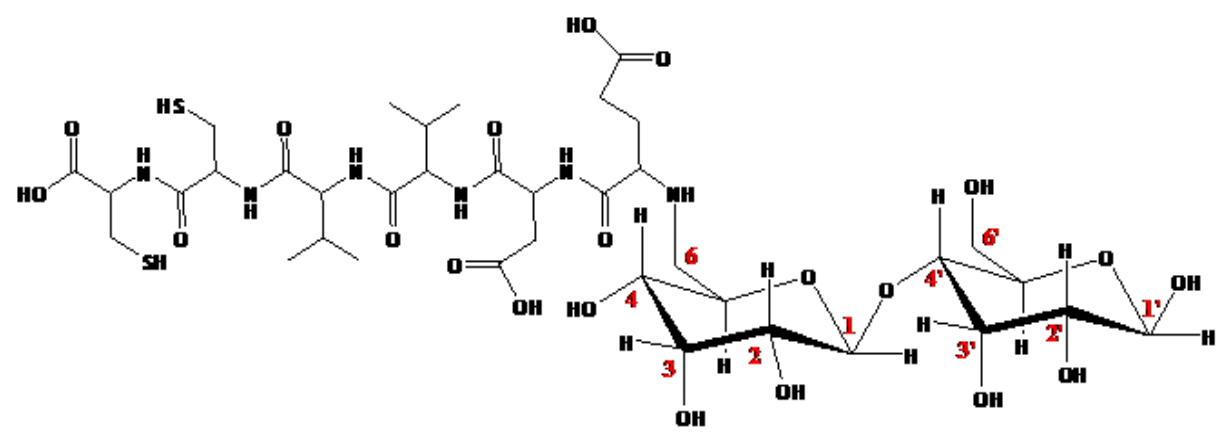

Fig. 1. The general structure of the previous studied compound at position 6 (cellulose dimer binding with hexapeptide[Gul-Asp-Val-Val-Cys-Cys] at position 6) 
a)

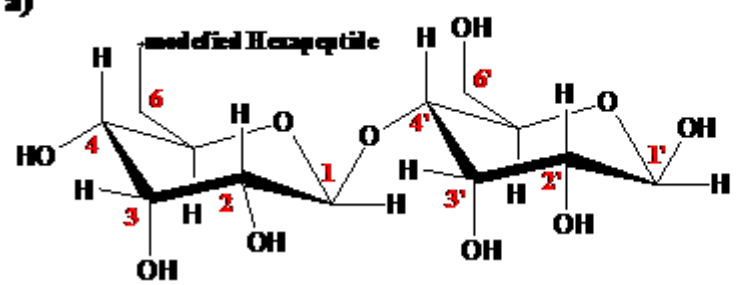

b)

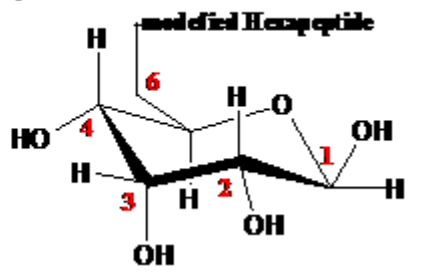

Fig.2. The general structure of the modified compounds. a) The first series. b) The second series.

TABLE 1. the description structure of studied compounds

\begin{tabular}{ll}
\hline Compound & The description structure \\
\hline $\mathbf{1}$ & dimer cellulose $+\beta$-amino acids. \\
\hline $\mathbf{2}$ & dimer cellulose + mix of $\alpha$ - and $\beta$-amino acids. \\
$\mathbf{3}$ & dimer cellulose $+\alpha$-ketoacids instead of the thiol group $(\mathrm{SH})$ of cysteine residues. \\
$\mathbf{4}$ & dimer cellulose + phenyl acyl sulfonamide instead of the $\mathrm{C}$-terminal carboxylic acid. \\
\hline $\mathbf{5}$ & $\quad \mathbf{2}^{\text {nd }}$ series \\
$\mathbf{6}$ & monomer cellulose $+\alpha$-amino acids. \\
$\mathbf{7}$ & monomer cellulose $+\beta$-amino acids. \\
$\mathbf{8}$ & monomer cellulose + mix of $\alpha$ - and $\beta$-amino acids. \\
$\mathbf{9}$ & monomer cellulose + phenyl acyl sulfonamide instead of the $\mathrm{C}$-terminal carboxylic acid. \\
\hline
\end{tabular}

mol and $-405473.66 \mathrm{kcal} / \mathrm{mol}$, respectively. The modified compounds with dimer cellulose (first series) are more stable than the parent compound at position 6. On the other hand, the compounds with monomer cellulose (second series) are less stable than the parent compound at position 6 (Table 2). The physical properties that determines the amount of changed total energy when neutral molecule gains an electron to form negative ion is called the electron affinity. The electron affinity of studied compounds areshown in Table 2 having values from $-0.031 \mathrm{eV}$ to $1.032 \mathrm{eV}$. All studied compounds except parent compound (at position 6) have positive sign of electron affinity values which point to the endothermic process associated with the additionof an electron to the modified compounds. The parent compound (at position 6) has negative sign which indicates that formation of negative ion of this compound is an exothermic process. Also, Table 2 lists the ionization potential which represents; the reverse of electron affinity; the energy required to remove an electron from the neutral molecule.Among the studied compounds, compounds 3 and 8 with $\alpha$-ketoacids need the lowest energy to lose an electron ( -10 $\mathrm{eV})$, while the parent compound at position 6 and compound 5 with $\alpha$-amino acids need the highest energy to remove an electron $(-8.6 \mathrm{eV})$. Frontier molecular orbital energy gap $(\Delta \mathrm{E})$ is equal to LUMO - HOMO and is represented in Table 2 for introduced compounds. LUMO is lowest unoccupied molecular orbital and HOMO is highest occupied molecular orbital. The $\Delta \mathrm{E}$ value of parent compound at position 6 is $8.62 \mathrm{eV}$. Compounds 4,5 and 9 have lower $\Delta \mathrm{E}$ value than that ofthe parent compound. That makes these compounds more reactive with other surrounding molecules than for parent compound. The rest of compounds have $\Delta \mathrm{E}$ more than that of the parent compound.Table 2 shows the heat of format of suggested compounds. The heat of formation represents the change in enthalpy during the formation of one mole of a compoundunder standard condition of one atmosphere at a given temperature.Compound 3 with $\alpha$-ketoacids has the lowest heat of formation $(-1164.86 \mathrm{kcal} / \mathrm{mol})$. This indicates thelowest change in enthalpy during the formation of its one mole and also indicates the stability of this compound. Compound 5 with $\alpha$-amino acids has the highest heat of formation value(-671.73 $\mathrm{kcal} / \mathrm{mol})$. The dipole moment represents the strength of interaction of themolecule with the electromagnetic wave due to the partial charge distribution within the molecule. From Table 2, the dipole moment of parent compound at position 6 is 4.31 Debye. The current modification of parent compounds in this study causes increase in the dipole moment 


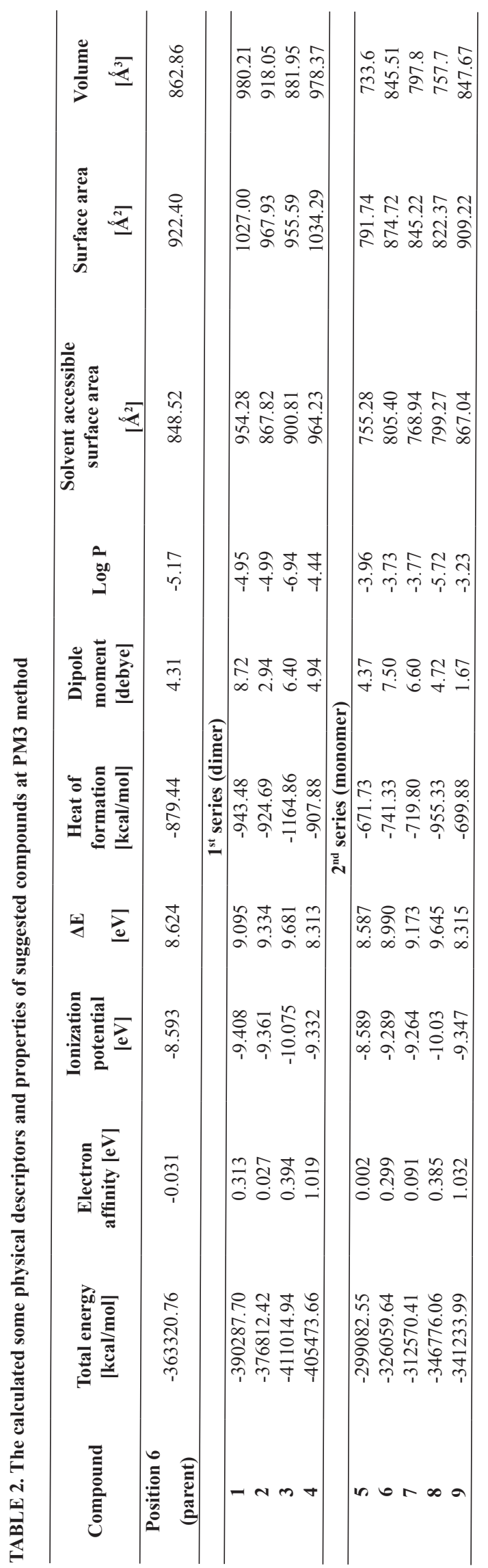

values except for compound 2 with mix of $\alpha$ - and $\beta$-amino acids and compound 9 with phenyl acyl sulfonamide; these two compounds have lower dipole moment. The solubility of compounds is determined by $\log \mathrm{p}$ descriptors. The molecule is hydrophobic, when $\log \mathrm{p}$ is a positive value. In contrast, the molecule is hydrophilic, when $\log$ $\mathrm{p}$ is negative value. As shown in Table 2, the $\log \mathrm{p}$ values of parent and modified compounds are negative and all compounds are hydrophilic and soluble in water. The $\log \mathrm{p}$ value of parent compound is -5.17 . The modification of parent compound causes a decrease in the solubility of all modified compounds except compound 3 and 8 with $\alpha$-ketoacids which are more soluble than parent compound. The surface areas of a molecule that are accessible to a solvent are listed in Table 2. The solvent-accessible surface area of the first series compounds are larger than corresponding compounds in second series. This is logically as the first series has dimer cellulose but the second series has monomer cellulose. The same trends in the values of surface area and volume are represented in Table 2. The surface area and volume of the first series are larger than that for the second series. This makes the second series probably suitable $\mathrm{HCV}$ NS3 protease inhibitors as this series have small molecules.

\section{The biological activity}

The biological activity of modified compounds are studied by calculating the docking interaction between the suggested compounds (ligands) and HCV NS3 protease active site. Fig. 4 shows the docking systems of ligands and HCV NS3 protease active site. In this figure, the yellow dashed lines represent the hydrogen bonds between the ligands and amino acid residues of protein, while the red dashed lines represent the hydrogen bonds within the ligands. Table 3 lists the total energy of docking systems, binding energy and the number of hydrogen bonds within the compounds (this number of H-bonds reflect the stability of compound in docking system) as well as hydrogen bonds between ligands and NS3 protease active site.Table 3 also shows the biological activity parameters of parent compound with position 6 [24].The total energy of docking interaction with suggested compounds varies from the lowest value; $393.54 \mathrm{kcal} / \mathrm{mol}$; for compound 6 with $\beta$-amino acids in second series to the highest value; $560.97 \mathrm{kcal} / \mathrm{mol}$; for compound 9 with phenyl acyl sulfonamidein second series. The docking system with compound 6 is most stable than compounds $1,5,7$ and 8 . The binding energy results in table 


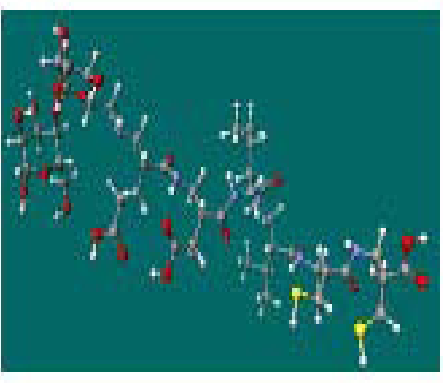

bompound 1

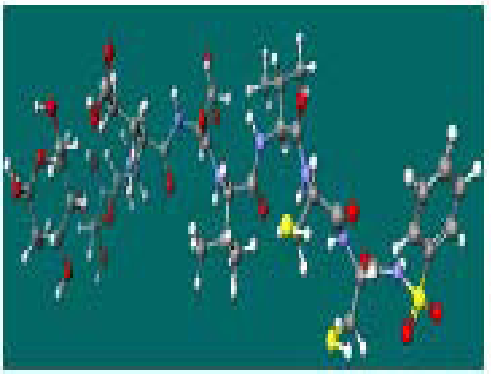

bompound

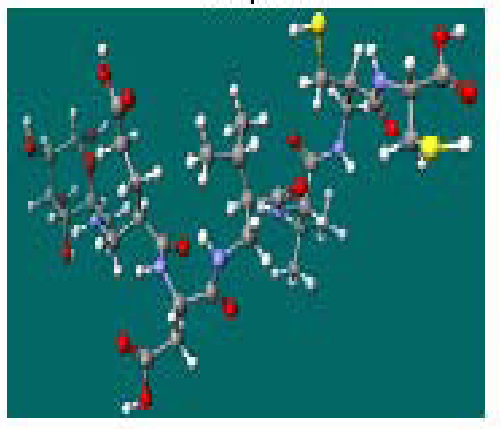

Gompond?

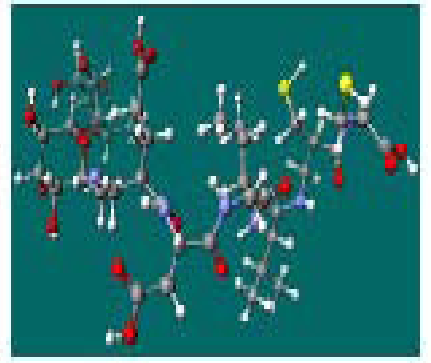

bompound?

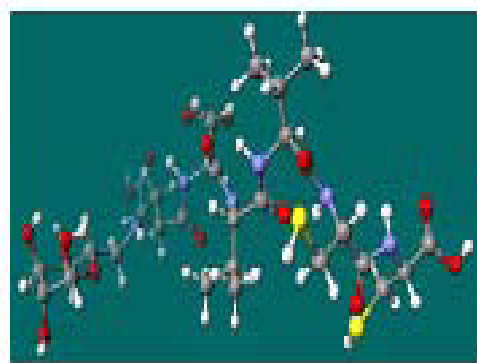

bompound 5

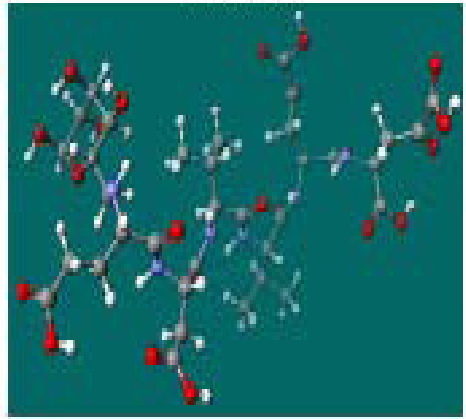

bompond

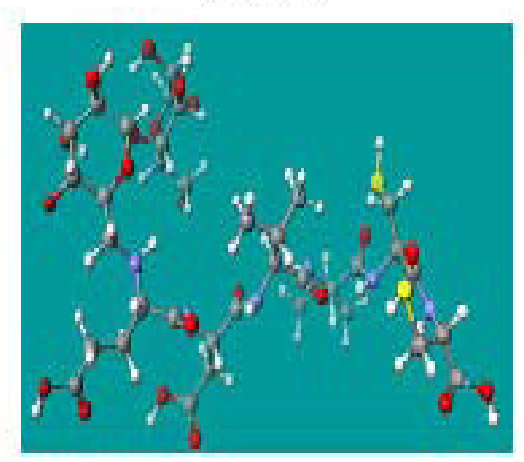

Pustion (f parat)

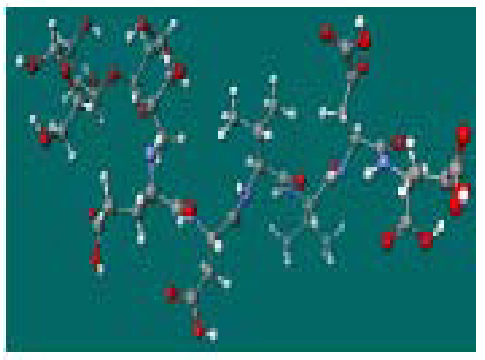

Dompund

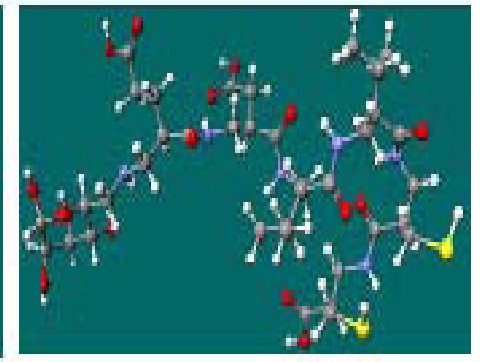

bompound f

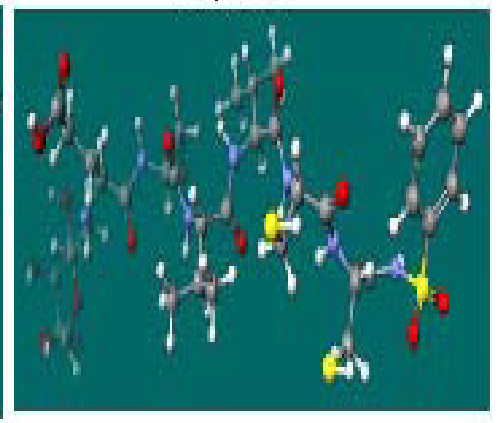

Bompunds

(n) 


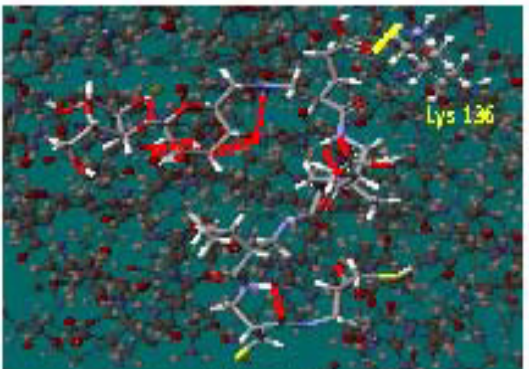

Compound 1

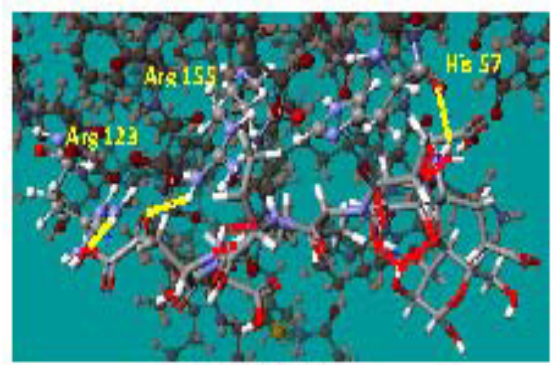

Compound 3

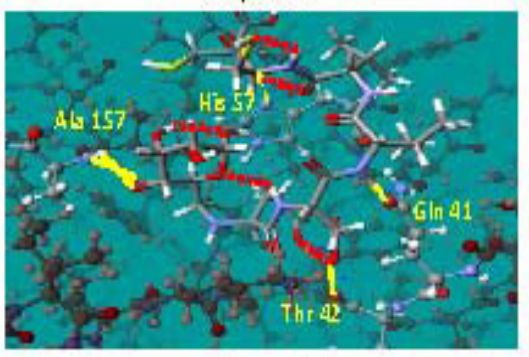

Compounds

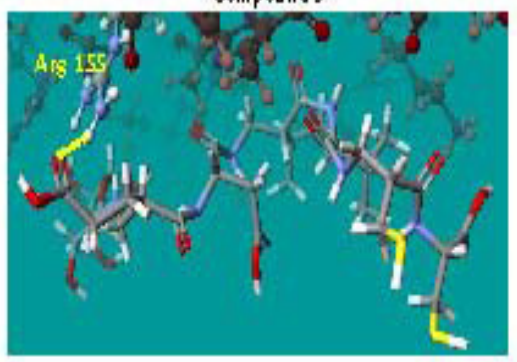

Compound 7

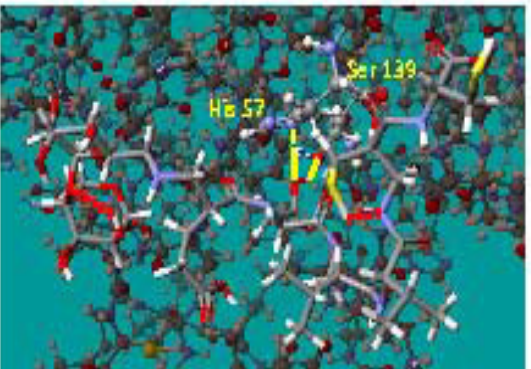

Compound 2

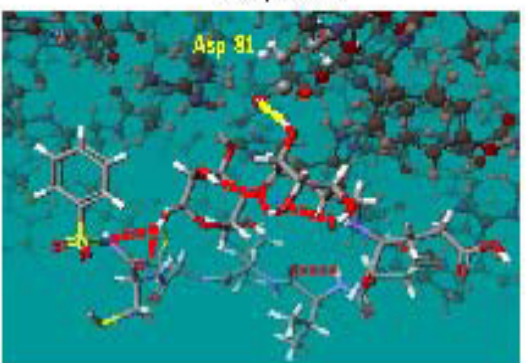

Compound d

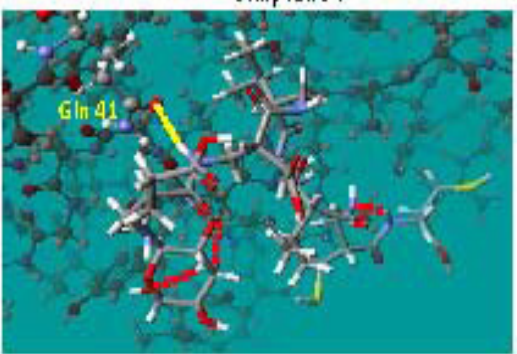

Compound 6

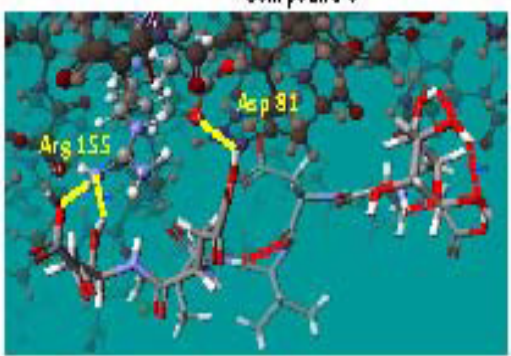

Compound B

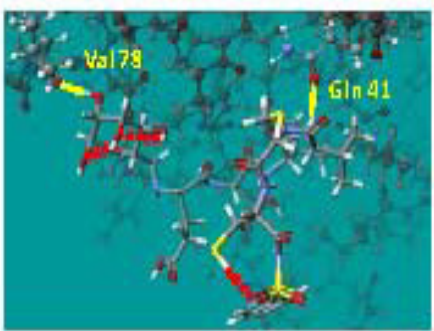

Compounds

Fig. 4 . The docking systems and mode of interaction between the ligands and HCV-NS3 protease. The cylindrical molecules represent the studied compounds and the ball \& cylinder molecules represent the amino acid residues of protein (The cyan, white, red, blue and yellow colors represent the carbon, hydrogen, oxygen, nitrogen and sulfur atoms, respectively). The yellow dashed lines represent the hydrogen bonds between the ligands and amino acid residues of protein, while the red dashed lines represent the hydrogen bonds within the ligands 
3 show that the two compounds with $\alpha$-ketoacids (compounds $3 \& 8$ ) in first and second series have the lowest binding affinity $(-97.77 \mathrm{kcal} / \mathrm{mol}$ and $-95.17 \mathrm{kcal} / \mathrm{mol}$ respectively). All compounds have negative binding energy except compound 9 with phenyl acyl sulfonamide which has positive binding energy.

The mode of binding between the studied compounds and HCV NS3 protease through hydrogen bonds as well as the number of hydrogen bonds participating in the binding are represented in figure 4 and Table 3 . Compound 1 with $\beta$-amino acids has the highest negative binding energy value $(-3.98 \mathrm{kcal} / \mathrm{mol})$ and it produces in the docking system seven H-bonds within the compounds. Three of them are within the dimer cellulose, one between the dimer and hexapeptide sequences and the rest three $\mathrm{H}$-bonds are within hexapeptide sequences. This compound also form one H-bond with HCV NS3 protease, especially with Lys 136 amino acid. Compound 6 with $\beta$-amino acids in second series produces the lowest total energy of docking system $(393.54 \mathrm{kcal} /$ mol) and forms three H-bonds within the ligand and one $\mathrm{H}$-bond in docking system with binding energy of $-33.29 \mathrm{kcal} / \mathrm{mol}$. The two H-bonds in compound 6 form within monomer cellulose and one H-bond forms within hexapeptide sequences. The only H-bond in docking system of ligand 6 is with Gln 41 amino acid.

The two compounds havingthe highest negative binding energy after compound 1 are compounds 2 and 7 (mix of $\alpha$ - and $\beta$-amino acids in first and second series). The binding energy of ligand 2 is $-12.73 \mathrm{kcal} / \mathrm{mol}$ which forms two H-bonds within the compound; one of them within dimer cellulose and the other within hexapeptide amino acids. Compound 2 produces two H-bonds with two amino acids in the active site of NS3 protease. These active site amino acids are Ser 139 and His 57. On the other hand, the binding energy of ligand 7 is $-16.34 \mathrm{kcal} / \mathrm{mol}$. This compound forms only one H-bond with Arg 155 without any H-bonds within the ligand.

The lowest binding energies of suggested compounds are associated with compounds 3 and 8 (with $\alpha$-ketoacids) which have $-97.77 \mathrm{kcal} /$ mol and $-95.17 \mathrm{kcal} / \mathrm{mol}$ binding energy values, respectively. In the first series, compound 3 has seven H-bonds. Three of them are within dimer cellulose and the rest four are within sequences of hexapeptide. The docking system of ligand 3 shows three H-bonds with NS3 protease at Arg 123, Arg 155 and active site His 57 amino acid. In compound 8 (second series), there are three $\mathrm{H}$-bonds within monomer cellulose and one $\mathrm{H}$-bond within hexapeptide sequences. Also there are three H-bonds with targeted protease, two of them with Arg 155 and one with active site Asp 81 amino acid.

One of the compounds with phenyl acyl sulfonamide(compound 4) has negative binding energy and another has positive binding energy value (compound 9). The binding energy of compound 4 in first series (with phenyl acyl sulfonamide) is $-24.75 \mathrm{kcal} / \mathrm{mol}$. Six H-bonds

TABLE 3. The biological activity and docking calculations of studied compounds via MM3

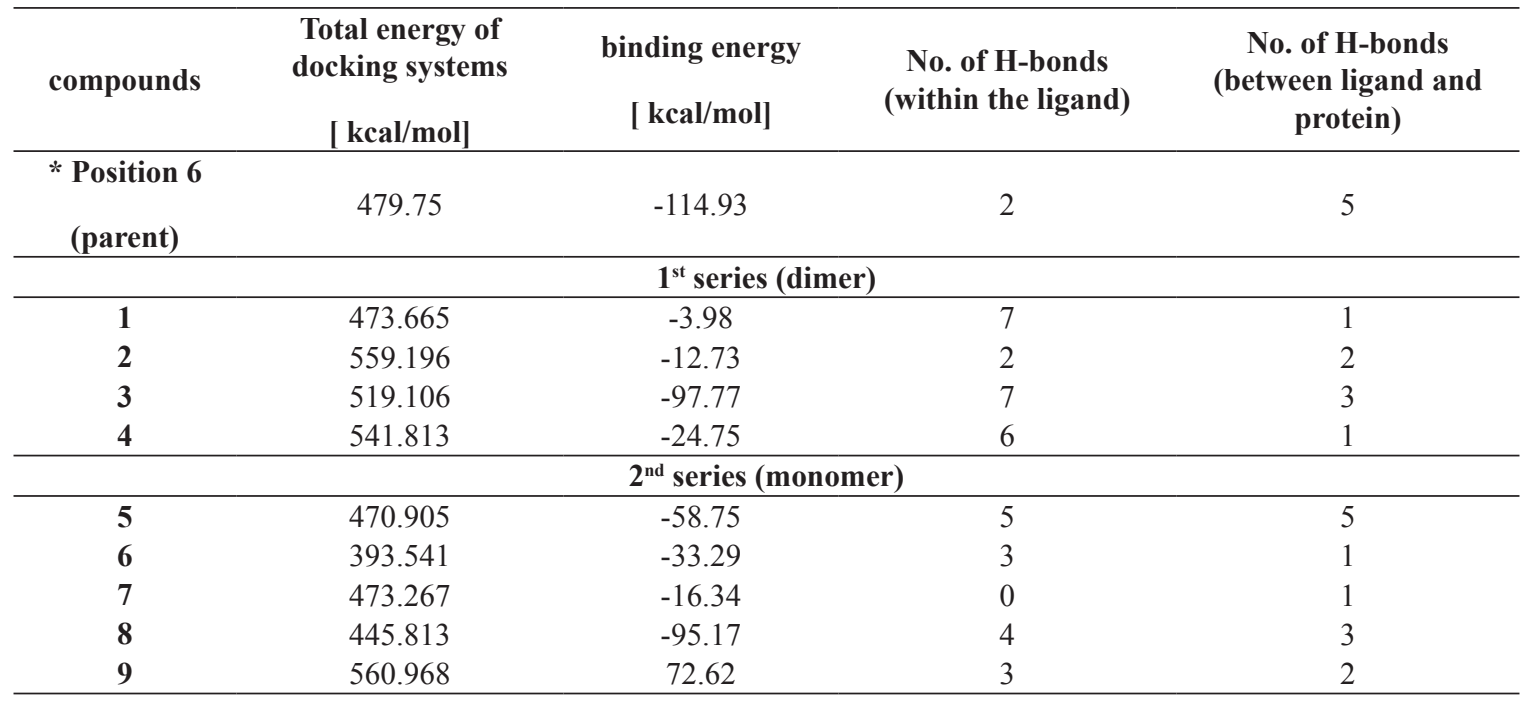

* Adapted from [24] 
form within ligand 4 (three H-bonds within dimer cellulose, one H-bond within hexapeptide sequences and two H-bonds between cellulose and hexapeptide). Only one H-bond is with Asp 81 active site residue of NS3 protease. On the other hand, compound 9 in the second series (with phenyl acyl sulfonamide) has positive binding energy value $(72.62 \mathrm{kcal} / \mathrm{mol})$ which is considered the highest binding energy among the represented compounds in this study. This compound forms two H-bonds within monomer cellulose and one $\mathrm{H}$-bond within hexapeptide sequences as well as two H-bonds with NS3 protease at Val 78 and Gln 41.

Finally, compound 5 with monomer cellulose and $\alpha$-amino acids has $-58.75 \mathrm{kcal} / \mathrm{mol}$ as a binding energy. Among the studied compounds, it forms the highest number of $\mathrm{H}$-bonds (five H-bonds) with NS3 protease and the same number of H-bonds as compared with parent compound. Two of these H-bonds with Ala 157 amino acid and the remainder three H-bonds with His 57 active site residue, $\mathrm{Thr} 42$ and Gln 41 . Compound 5 also produces five H-bonds within itself; one within monomer cellulose, three within sequences of hexapeptide and one between cellulose and hexapeptide.

\section{Conclusion}

The suggested modified compounds have different physical and biological properties compared with the unmodified parent compound (dimer cellulose with hexapeptide sequences at position 6).

According to the physical properties results, the first series is more stable than parent compound (low total energy and heat of formation values), while the second series is less stable than parent compound (high total energy and heat of formation values, except the compound 8 which has lower heat of formation). Compounds 3 and 4 (with $\alpha$-ketoacids compounds) are more hydrophilic (low $\log$ p) than the unmodified compound. In contrast, all other studied compounds are less hydrophilic. Only compounds 2 and 9 have lower dipole moments compared with that of parent compound at position 6 , while the rest of compounds have higher dipole moment values. Based on the atomic composition of suggested compounds, the first series has larger solvent accessible surface area, surface area and volume compared to the second series.
Depending on the present results of biological activity and comparison with parent compound, the compounds of the first series have less docking system stability except compound 1.The second series compounds are more stable in docking systems except compound 9. The binding energy of the compounds with $\alpha$-ketoacids from the two series have nearly similar values to that of parent compound.

In conclusion, the two compounds with $\alpha$-ketoacids in the first and second series (compound 3 and 8 ) have better physical properties (lowest heat of formation, high dipole moment and more hydrophilic) as well as nearly similar biological activity (lower binding energy with NS3 protease active site) compared to the recently studied inhibitor without any modifications. In future studies, thesechosen two compounds 3 and 8 with potential inhibition activity against $\mathrm{HCV}$ NS3 protease will be chemically synthesized and experimentally studied.

\section{Acknowledgment}

The author would liketo thank Prof. Dr. Wael M. Elshemey, biophysics department, Faculty of Science,Cairo University for valuable comments that greatly improved the manuscript.

\section{References}

1. Leach, A.R., "Molecular Modelling Principle and Applications", Addison Wesley Longman Limited, Edinburgh Gate, Harlow, Essex CM20 2JE, England, p. 640 (1996).

2. Cohen, N.C. "Guidebook on Molecular Modeling in Drug Design”, Academic press, Inc. (1996).

3. Cramer, C.J., "Essentials of Computational Chemistry Theories and Models" Second edition, John Wiley \& Sons Ltd, The Atrium, Southern Gate, Chichester, West Sussex PO19 8SQ, England, p1 (2004).

4. Hinchliffe, A., "Molecular Modelling for Beginners", Second edition JohnWiley \& Sons Ltd, p37 (2008).

5. Jensen, J.H., "Molecular Modeling Basics" Taylor and Francis Group, LLC, p103 (2010).

6. Lewars, E.G., "Computational Chemistry Introduction to the Theory and Applications of Molecular and Quantum Mechanics" Third edition, Springer International Publishing Switzerland, p1 (2016). 
7. Lundblad, R.L., Encyclopedia of Cell Biology, 1, 135 (2016)

8. MerzJr. K.M., Ringe, D. and Reynolds, C.H. "Drug Design: Structure- And Ligand-Based Approaches" Cambridge University Press (2010)

9. Taft, C.A., Silva V.B. and Silva, C.H.T.P., J. Pharm. Sci. 97, 1089 (2008).

10. Aguayo-Ortiz, R., and Gortari, E.F., "Overview of Computer-Aided Drug Design for Epigenetic Targets" Chapter 2, Elsevier Inc. (2016)

11. Huang, H., Yu, H.W., Chen, C., Hsu, C., Chen, H., Lee, K., Tsai, F.and Chen, C.Y., J. Taiwan. Inst Chem. E., 41, 623 (2010).

12. Warren, G.L., Do, T.D., Kelley, B.P., Nicholls, A. and Warren, S.D., Drug Discov. Today, 17, (2324), 1270 (2012)

13. Zheng, M., Liu, X., Xu, Y., Li, H., Luo, C. and Jiang, H., Trends Pharmacol. Sci., 34, 549 (2013).

14. Pei, J., Yin, N., Ma, X. and Lai, L., J. Am. Chem. Soc., 136, 11556 (2014)

15. Chen, Y., Beware of docking!, Trends Pharmacol. Sci., 36, 78 (2015)

16. Ibrahim, M., Saleh, N.A. and Elshemey, W.M., Khan, M.T.H.(Editor) "Recent Trends on QSAR in the Pharmaceutical Perceptions", Bentham Science Publisher, Netherlands, p. 360 (2012).

17. Davis, A.M., Encyclopedia Comprehensive Medicinal Chemistry, III, 379, (2017).

18. Ibrahim M., Saleh, N.A., Elshemey, W.M. and Elsayed, A.A., J. Comput. Theor. Nanosci. 10 (4), 785 (2013)

19. Weidlich, I.E., Filippov, I.V., Brown, J., KaushikBasu, N., Krishnan, R., Nicklaus, M.C. and Thorpe, I.F., Bioorgan. Med. Chem., 21, 3127 (2013)

20. Saleh, N.A., Elfiky, A.A., Ezat, A.A., Elshemey, W.M. and Ibrahim, M., J. Comput. Theor. Nanosci. 11(2), 544 (2014)

21. Mostafa, H.I.A., El-Bialy, N.S., Ezat, A.A., Saleh, N.A., and Ibrahim, M., Curr. Comput.-Aid Drug, 10 (1), 28 (2014).

22. Saleh, N.A., Ezat, A.A., Elfiky, A.A., Elshemey, W.M. and Ibrahim, M., J. Comput. Theor. Nanosci. 12, 371 (2015).

23. Saleh, N.A., Elhaes, H. and Ibrahim, M., "Design and Development of Some Viral Protease Inhibitors by QSAR and Molecular Modeling Studies" a book chapter in "Viral Proteases and Their Inhibitors" Elsevier, DOI:10.1016/B978-012-809712-0.00002-2., p 25, (2017).

24. Saleh, N.A. and Elshemey, W.M., Life Science, 187, 58 (2017)

25. Balasubramanian, K. and Patil, V.M., Comput. Biol. Chem., 73, 147 (2018).

26. Elfiky, A.A. and Ismail, A.M., Future. Virol. 12 (7), 339 (2017).

27. Elfiky, A.A., Mahdy, S.M. and Elshemey, W.M., $J$. Med. Virol. 89 (6), 1040 (2017)

28. Choo, Q.L., Kuo, G., Weiner, A.J., Overby, L.R., Bradley, D.W. and Houghton, M., Science, 244, 359 (1989)

29. Patel, P.D., Patel, M.R., Basu, N.K. and Talele, T.T., J. Chem. Inf. Model. 48, 42 (2008).

30. MohdHanafiah, K., Groeger, J., Flaxman, A.D. and Wiersma, S.T., Hepatology, 57, 1333 (2013)

31. Hirashima, S., Suzuki, T., Ishida, T., Noji, S., Yata, S., Ando, I., Kamatsu, M., Ikeda, S. and Hashimoto, H., J. Med. Chem. 49, 4721 (2006).

32. Ghany, M.G., Strader, D.B., Thomas, D.L., Seeff, L.B., Hepatology, 49, 1335 (2009)

33. Francesco, R.D., Hepatology, 31, 47 (1999).

34. McLauchlan, J., J. Viral Hepat., 7, 2 (2000).

35. Moradpour, D., Penin, F. and Rice, C.M., Nat. Rev Microbiol. 5, 453 (2007).

36. Ashfaq, U.A., Javed ,T., Rehman, S., Nawaz, Z. and Riazuddin, S., Virol. J., 8,161 (2011).

37. Moradpour, D. and Penin, F., Curr. Top. Microbiol. Immunol., 369, 113 (2013).

38. Atoom, A.M., Taylor, N.G. and Russell, R.S., Virology, 462-463, 377 (2014).

39. Rodríguez-Rodrígueza, M., Telloa, D., GómezGutiérreza, J., Peterson, D.L., Gavilanesa, F. and Yélamosa, B., BBA-Biomembranes, 1860, 728 (2018)

40. Tibbs, C.J., Trans. R. Soc. Trop. Med. Hyg., 91, 121 (1997).

41. Timm, J., Neukamm, M., Kuntzen, T., Kim, AY., Chung, R.T., Brander, C., Lauer, G.M., Walker, 
B.D. and Allen, T.M., Viral Hepatitis, 14, 330 (2007)

42. Kamal, S.M. and Nasser, I.A., Hepatology, 47 (4), $1371(2008)$

43. McHutchison, J.G., Gordon, S.C., Schiff, E.R., Shiffman, M.L., Lee, W.M., Rustgi, V.K., Goodman, Z.D., Ling, M.H., Cort, S. and Albrecht, J.K., N. Engl. J. Med., 339, 1485 (1998)

44. Par, A., Telegdy, L., Dalmi, L. and Muller, E., J. Physiology-Paris, 95, 399 (2001)

45. Taylor, D.R., Shi, S.T. and Lai, M.M.C., Microbes Infect., 2, 1743 (2000)

46. Carnero, E. and Fortes, P., Virus Research, 212, 85 (2016)

47. Poordad, F. and Dieterich, D., J. Viral. Hepat.,19, 449 (2012)

48. Zhang, X., Acta PharmaceuticaSinica B, 6 (1), 26 (2016)

49. Nurbo, J., Peterson, S.D., Dahl, G., Danielson, U.H., Karlen, A. and Sandstrom A., Bioorg. Med. Chem., 16, 5590 (2008).

50. Narjes, F., Brunetti, M., Colarusso, S., Gerlach, B., Koch, U., Biasiol, G., Fattori, D., De Francesco, R., Matassa, V.G. and Steinkühler, C., Biochemistry, 39 (7) 1849 (2000)

51. Colarusso, S., Gerlach, B., Koch, U., Muraglia, E., Conte, I., Stansfield, I., Matassa, V.G. and Narjes, F., Bioorg. Med. Chem. Lett. 12, 705 (2002)
52. Nizi, E., Koch, U., Ponzi, S., Matassay, V.G. and Gardelli, C., Bioorg. Med. Chem. Lett. 12, 3325 (2002)

53. Ronn, R., Sabnis, Y.A., Gossas, T., Akerblom, E., Danielson, U.H., Anders Hallberga, A. and Johansson, A., Bioorg. Med. Chem., 14, 544 (2006)

54. Johansson, A., Poliakov, A., Akerblom, E., Wiklund, K., Lindeberg, G., Winiwarter, S., Danielson, U.H., Samuelssonc, B. and Hallberga A., Bioorg. Med. Chem., 11, 2551 (2003)

55. Stewart, J.J.P., SCIGRESS, Version 2.9.0, Fujitsu Limited, United States, (2009).

56. Stewart, J.J.P., J. Comput. Chem., 10, 209 (1989).

57. Bennett, F., Huang, Y., Hendrata, S., Lovey, R., Bogen, S.L., Pan, W., Guo, Z., Prongay, A., Chen, K.X., Arasappan, A., Venkatraman, S., Velazquez, F., Nair, L., Sannigrahi, M., Tong, X., Pichardo, J., Cheng, K.C., Girijavallabhan, V.M., Saksena, A.K. and Njoroge, F.G., Bioorg. Med. Chem. Lett., 20, 2617 (2010).

58. Lii, J. and Allinger, N.L., J. Am. Chem. Soc., 111, 8576 (1989)

59. Muegge, I., Perspect. Drug Discov. Des., 20, 99 (2000)

(Received: 3 /5 /2018; accepted: $19 / 6 / 2018$ ) 
الجديائص الفيزيائية والنشاط الحيوي لبعض مثبطات الأنزيم البروتيني NS3 HCV

نهم صالح

قهم الفيزياء الحيوية ـ كلية العلوم - جامعة القاهرة ـ الجيزة ـ مصر

تحاكي النمذجة الجزيئية النظرية الخصائص الفيزيائية والكيميائية والبيولوجية وسلوك الجزيئات باستخدام

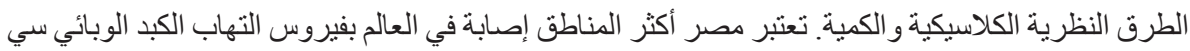

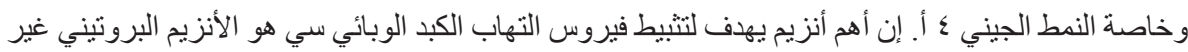

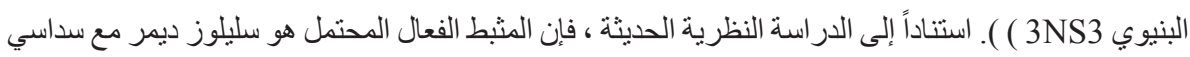

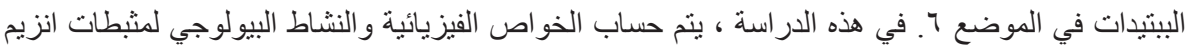
البروتيز NS3 الجديدة المقترحة للنمط الجيني ؛ الخاص بمصر باستخدام طريقة PM3 ـ وتنقسم هذه المثبطات

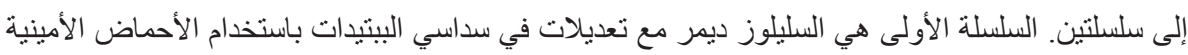

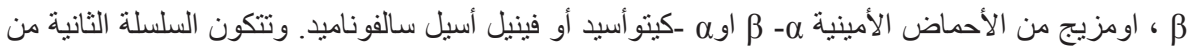

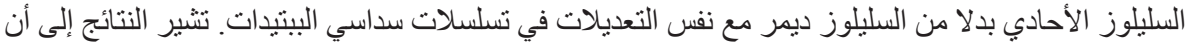

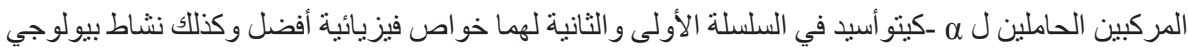
مماتل تقريبا مقارنة بالمثنط الذي تمت در استه مؤخر ا دون أي تعديلات. 